\title{
Credentials of astro-archeology
}

\author{
A. J. Meadows
}

Megaliths, Myths and Men: An Introduction to Astro-Archaeology. By Peter Lancaster-Brown. Pp. 324. (Blandford: Poole, Dorset, 1976.) $£ 4.75$.

Is there such a subject as astro-archaeology? The word obviously implies not only that pre-literate cultures possessed an astronomical tradition, but also that some part of the tradition can be retrieved from surviving artefacts. The most frequently cited instance of such retrieval-and the one that forms the theme of this book-is provided by the megaliths and their alleged orientation towards astronomically significant points on the horizon. The problem is the degree of certainty that can be attached to any conclusions-after all, some of the proposed orientations, with their accompanying interpretations, are still in dispute today after nearly a century of discussion.

A central difficulty is that we are not dealing with a single debate, but with a range of topics not all of which are contested with equal vigour. At one extreme, there is the basic question -Do any astronomically significant orientations of megaliths indisputably exist? Then, somewhere in the middle, one might ask whether astronomically sophisticated orientations-for example, to particular bright stars-occur. At the other end of the spectrum, can any significance at all be attached to the so-called 'leys'-that is, alleged alignments of widely differing prehistoric features, often over considerable distances?

$\mathrm{Mr}$ Lancaster-Brown's book, which examines all these questions, is intended for the uninitiated. Technical astronomy is not avoided, but the necessary concepts and jargon are introduced as the need arises. A genuine beginner may find the problems of the celestial sphere occasionally hard to visualise, but the explanations are generally clear. The text is primarily concerned with present-day attitudes, but we are also given an extended survey of the historical development of interest in the subject. These two themes are by no means distinct, for part of the continuing controversy over the credentials of astro-archaeology has derived from the excessive claims of some of its past adherents. A short diversion outside
Western Europe to examine pyramidology ties in both with the main discussion of astronomically oriented monuments, and with a subsidiary question that has often been raised simultaneously: whether or not the builders of megalithic structures used a standard measure of length.

In terms of our initial range of topics, as $\mathrm{Mr}$ Lancaster-Brown notes, the majority of people who have examined megaliths now believe that astronomical orientation of some sort is certainly present. At the other extreme, few-except occultists-give much credence to leys. But the uncertain area remains the exact level of astronomical sophistication enshrined in the megaliths. Quite clearly, opinion in recent years has tended to allow our distant ancestors a more detailed aquaintance with astronomy than hitherto. This change has been partly caused by the accumulation of data from new and more detailed surveys: but partly it stems from a somewhat greater willingness on the part of archaeologists to accept that our ancestors were actually capable of such sophistication. It is unfortunate in this respect that so much space in the book is devoted to Stonehenge, since, although it may be fascinating from the point of view of speculative astronomy, it is one of the astronomically overexplained monuments in the eyes of archaeologists. Again, archaeologists might wish to quibble at one or two omissions from the list of select references. But the book adequately fulfills its role as an introductory survey.

Professor Meadows is Head of the Department of Astronomy and History of Science at the University of Leicester, $U K$.

\section{Soil science and archeology}

Soil Science and Archaeology. By Susan Limbrey. Pp. 384. (Academic: London.) $£ 8.40$.

IN recent years there has been a marked increase in the application of science to archaeology, but soil science has tended to be underemphasised; this book corrects such a deficiency. The first part of the book summarises the nature of soil properties and pedogenesis. These principles are demonstrated in the following two parts by the description and evolutionary analysis of soils from selected environments. In the fourth part attention is focused on the archaeological attributes of soils.

The inevitable problem with a book of this title is defining the audience to whom it is addressed; it could have been written as a research text for soil scientists involved with archaeology or as an introductory text on soils relevant to field archaeologists. Instead it is written for archaeologists at all levels, but many will find the first part hard going, since a firm scientific background is assumed. Indeed the first three parts will prove to be of great use to students of soil science per se; in particular, the chapters on the history of podzolised and chalk soils in Britain are scholarly articles in their own right.

The only general criticism which can be made is that the reader will not gain detailed advice on how to carry out various procedures-for example, the classification and mapping of soils. A common request to a soil scientist on an archaeological project is a soil or terrain map, and the fieldwork has usually to be completed within a short field season. A demonstration of the necessary techniques could have centred around the greater use of examples and illustrations.

But Dr Limbrey has produced an authoritative text which deserves a wider audience than its title might imply. The usefulness of soil science to archaeology is very well demon. strated, and the potential contribution of archaeology to our understanding of soil evolution is equally stressed.

Donald A. Davidson

Donald Davidson is a lecturer in the Department of Geography at the University of Strathclyde, UK. 